\title{
Decipherment of the Indus script
}

This paper describes a decipherment of the Indus script. The decipherment is based on observed similarities between Protocuneiform script and the Indus script. Meanings were transferred from Protocuneiform characters to characters in Indus script, and Dravidian words were used to obtain sounds for Indus script characters. Correlation between Brahmi letters and corresponding Indus characters were further used to correct the readings obtained. These readings show that Indus civilisation was largely Dravidian. It also shows that caste divisions specific to modern South India existed in Indus civilisation. Representative caste names can still be identified in North and South India. These readings also establish with a high probability that Protocuneiform script influenced the Indus script and that Brahmi script, at least partially, originated from the Indus script.

\section{Abbreviations used}

MEA- Manuel D, Epigraphie Akkadienne

CP-Corpus of Indus seals and inscriptions - Pakistan

Cl- Corpus of Indus seals and inscriptions- India

IVC- Indus valley civilisation

The Protocuneiform script is considered to be the earliest form of writing. Egyptian cuneiform and other scripts are widely held to be derived from the Protocuneiform script.

Indus valley script is attested from as early as $33^{\text {rd }}$ century BC. The language used is unknown though generally believed to be Dravidian.

This paper is derived from similarities observed between Indus (IVC) characters and Protocuneiform characters. Meanings of individual Protocuneiform characters were transferred to IVC characters and Dravidian words were used to identify phonemes for the characters. These sounds were used to read specific seals. Only about 20 IVC characters have been so far deciphered to any degree of 
certainty. These comprise about 5 percent of the characters in the complete script. Only about $30-$ 40 seals can be read with any degree of certainty. But these readings do provide a fairly good understanding of the Indus valley civilisation.

The Protocuneiform signs and word meanings used here are derived from Manuel D'épigraphie Akkadienne by Labat(MEA). (Labat.R)

Indus seals are as described in Corpus of Indus Seals and Inscriptions 1 \& 2 by A.Parpola. (A.Parpola, 1987)Access to both these works would be of great advantage in reading this paper.

Brahmi script is available online from several source. (Omniglot, n.d.)

\section{Certain aspects about the readings}

All these works are inherently probabilistic in nature. The primary language used here seems to be Dravidian but is probably different from all Dravidian languages as they are now. Only aspects of the language which have stayed stable over 4 millennia can be recognized. These are generally caste names and certain divisions in society. Most of the readings which can be made are partial with only certain portions of a seal in a readable state. The readings seem to indicate the presence of Dravidian caste divisions, in particular, a form of division called the Idangai Valangai division in the Indus valley. Idangai and Valangai respectively mean Right Hand and Left hand respectively and were broad divisions across castes in South India. This division is explained in detail later on. 


\section{Sign List}

Table 1

\begin{tabular}{|c|c|c|c|}
\hline $\begin{array}{l}\text { Indus } \\
\text { Character }\end{array}$ & $\begin{array}{l}\text { Protocuneiform } \\
\text { Character } \\
\text { \&Meaning }\end{array}$ & $\begin{array}{l}\text { Brahmi } \\
\text { Letter }\end{array}$ & Sound values assigned and remarks \\
\hline & $\left(\begin{array}{l}1,1 \\
11 \\
11 \\
11\end{array}\right)$ & $\frac{I}{\text { ṇa }}$ & $\begin{array}{l}\text { AN } \\
\text { This has been read as "An" by several authorities. } \\
\text { 'This has been generally called the "Vase sign" or the } \\
\text { "jar sign". This is actually a phallic symbol and is } \\
\text { related to the Protocuneiform "Lugal" sign. The } \\
\text { Brahmi character for "na "is also a phallic symbol and } \\
\text { is derived from this. "An "basically means "Male" in } \\
\text { almost all Dravidian languages. }\end{array}$ \\
\hline & & & $\begin{array}{l}\text { MIN } \\
\text { I. Mahadevan has read this symbol as "Min". I read } \\
\text { this in the same way. The Brahmi "Ma" seems derived } \\
\text { from this. With diacritics this can be read as "Ma "etc. }\end{array}$ \\
\hline & & $\Gamma_{\mathrm{da}}$ & $\begin{array}{l}\text { DA } \\
\text { This is similar to the water sign from Protocuneiform. } \\
\text { The word for water in Tamil is "Thanni". However, this } \\
\text { character seems to sound as "Da" and is probably } \\
\text { derived from the Brahui word for water," Deer". } \\
\text { Derivation of this character is detailed in the section } \\
\text { on Pasupathi seal. The Brahmi letter for "Da" is } \\
\text { derived from this. }\end{array}$ \\
\hline & & $\begin{array}{l}\text { 平 } \\
\text { kai }\end{array}$ & $\begin{array}{l}\text { KAl } \\
\text { This is the Indus valley "Hand Symbol" This is read as } \\
\text { "Kai". This is cognate to the Sumerian Hand symbol, } \\
\text { Chinese hieroglyphic hand symbol etc. Brahmi letter } \\
\text { "Kai" is derived from this. This is one of the most } \\
\text { important symbols in this corpus and finding this } \\
\text { reading was the key to the decipherment of all the } \\
\text { other readings. Reading this enabled the reading of } \\
\text { certain seals as Idangai and Valangai. }\end{array}$ \\
\hline & & & $\begin{array}{l}\text { KAl } \\
\text { This character is also read with the same sound as } \\
\text { "Kai". This is probably similar to the Protocuneiform } \\
\text { word for the date palm. The word for palm in several } \\
\text { Indian languages is Kaira, Kaitha etc. Several other } \\
\text { characters have the same sound. This is called } \\
\text { homophony and is seen in Sumerian as well. }\end{array}$ \\
\hline
\end{tabular}




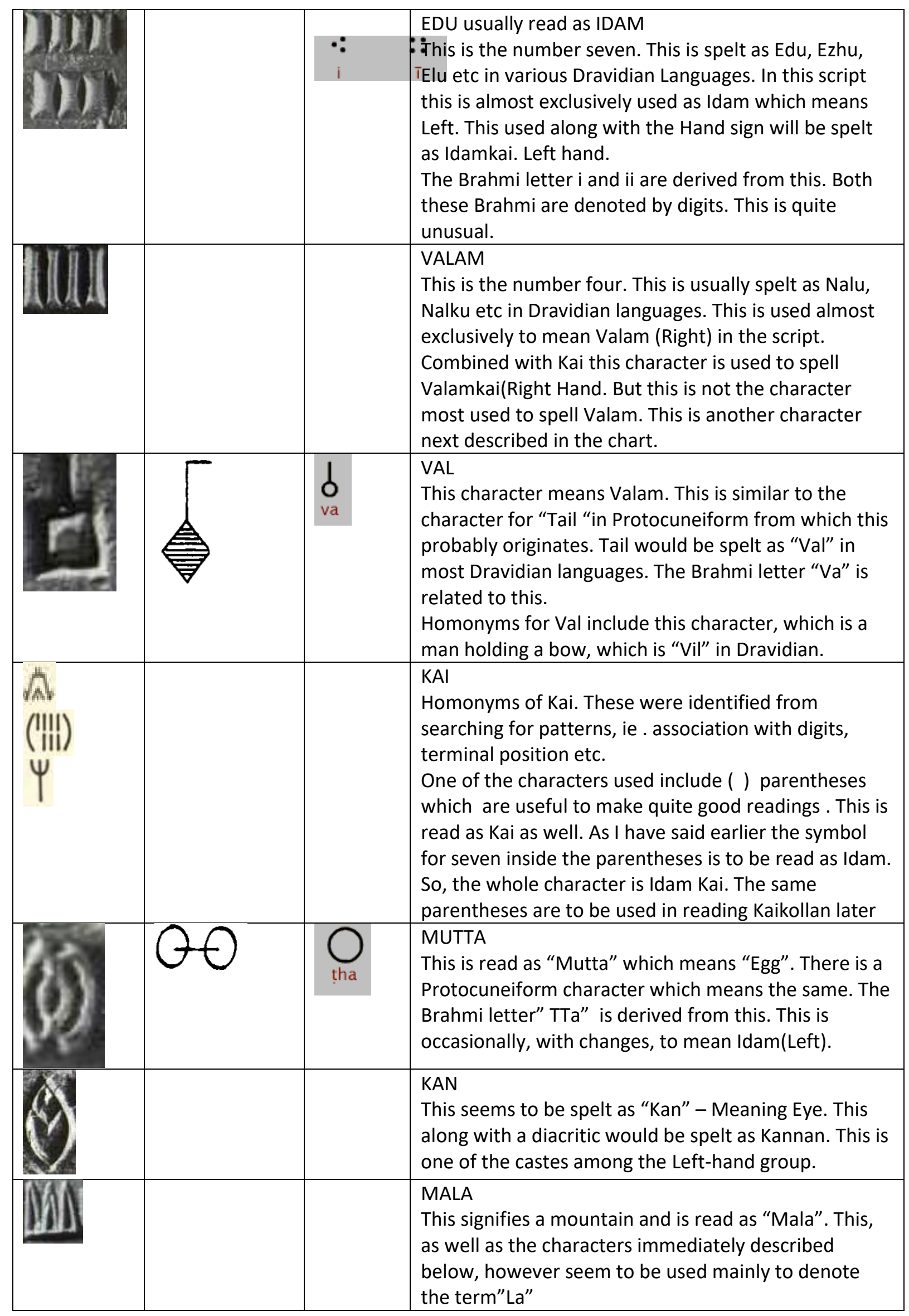




\begin{tabular}{|c|c|c|c|}
\hline 1) & & & $\begin{array}{l}\text { MALAR } \\
\text { This is a flower and is read as "Malar". This is used as } \\
\text { explained above. }\end{array}$ \\
\hline & & & $\begin{array}{l}\text { VALA } \\
\text { This is "Vala" meaning "Net". This is similar to the } \\
\text { character used for cloth in Protocuneiform. This also } \\
\text { used predominantly as "La" }\end{array}$ \\
\hline & & & $\begin{array}{l}\text { KAIKOLLAN } \\
\text { This shows a hen surrounded by parentheses. The } \\
\text { standard word for hen is Koli in most Dravidian } \\
\text { languages. The parentheses are to be read as "Kai" } \\
\text { and the diacritic on the left is "An".Mainly used to } \\
\text { denote Kaikollan ie. a weaver. }\end{array}$ \\
\hline & & $\bigwedge_{\text {śa }}$ & $\begin{array}{l}\text { SALIYA } \\
\text { This is a spider. Spelled as Silanti, Saliyan etc. Basically, } \\
\text { used to denote a caste called Saliyan, ie. Weaver }\end{array}$ \\
\hline & & & $\begin{array}{l}\text { AN } \\
\text { This is used as a diacritic to denote An/ Ar/ Ari. The } \\
\text { Brahmi diacritics of An and i, ii. Seem to be derived } \\
\text { from this }\end{array}$ \\
\hline & & & $\begin{array}{l}\mathrm{ZU} \\
\text { "Zu". This means Knowledge, Wisdom etc in } \\
\text { Sumerian. This seems to be used as Anch". This is a } \\
\text { very uncertain reading }\end{array}$ \\
\hline & & & $\begin{array}{l}\text { LA } \\
\text { This is spelt as La. This seems to be used } \\
\text { predominantly to spell "Anchalan". }\end{array}$ \\
\hline & UDU(GOAT) & & $\begin{array}{l}\text { DA } \\
\text { This is similar to the Protocuneifrom sign for Goat. The } \\
\text { origin of this sign in Protocuneiform is uncertain but } \\
\text { was probably used with a similar sound in Indus script. }\end{array}$ \\
\hline & & & $\begin{array}{l}\text { PAR } \\
\text { This is the sign used in Protocuneiform to denote side. } \\
\text { The Dravidian word Puram - the other side is probably } \\
\text { related to this. }\end{array}$ \\
\hline & & & $\begin{array}{l}\text { RU. } \\
\text { The Protocuneiform sound is KUR and means } \\
\text { stranger, opponent etc. the Dravidian word for } \\
\text { opponent is Ethirali, Etiri etc, Brahmi vowel 'R" } \\
\text { seems derived from this. }\end{array}$ \\
\hline
\end{tabular}




\section{Uncertain readings}

Some readings are partial and uncertain. It is possible to know the meanings of certain readings, but it is not possible at this stage to know the exact sounds used. These are given below. Readings based on these characters are not described in this paper.

Table 2

\begin{tabular}{|l|l|}
\hline & $\begin{array}{l}\text { THALA } \\
\text { This probably means a head and is probably } \\
\text { derived from the Protocuneiform word for Head } \\
\text { "Sig". Thala is the possible sound used. Very } \\
\text { uncertain reading. }\end{array}$ \\
\hline$y$ & $\begin{array}{l}\text { KUR/ PAL } \\
\text { This is probably a word for teeth and is derived } \\
\text { from the Protocuneiform word "Gu". But the } \\
\text { Protocuneiform word itself has multiple meanings } \\
\text { and can mean Cry, Teeth, mouth etc. }\end{array}$ \\
\hline & $\begin{array}{l}\text { This is a leaf and is derived from the } \\
\text { Protocuneiform word "Til". The precise sound } \\
\text { however is not certain. }\end{array}$ \\
\hline & $\begin{array}{l}\text { This is the Protocuneiform sun sign. This is spelt } \\
\text { "Utu" in Sumerian and is probably similar to } \\
\text { "Aditya" in Dravidian. Again, uncertain reading. } \\
\text { "Dha"in Brahmi is probably derived from this. } \\
\text { Uncertain readings can be made using "Aa "sound } \\
\text { for this character. }\end{array}$ \\
\hline
\end{tabular}

Using these sound values various readings can be obtained. These initial readings can then be logically extended to read further characters. This has been the method used to obtain readings so far. 


\section{Pashupati seal}

The Pashupati seal is the first seal which I will attempt to read. The sound values are given below. Question marks denote sounds which are unknown.

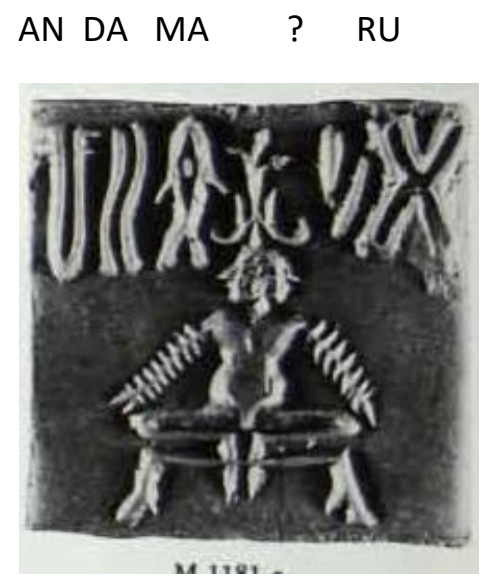

RU ?MA DA AN

Fig -1 CP - Page 138-M1181

This reading is incomplete. This is the first seal which I could read to any degree of certainty. This is to be read from right to left. The first letter is " $X$ ". This is similar to a Protocuneiform character called "KUR". (MAE- Page 62). This generally means opponent, hostile, stranger etc. The words in most Dravidian are "Ethiri", "Ethirali" etc. The Brahmi letter " $\mathrm{X}$ " sounds as " $\mathrm{R}$ ". I have preferred to use the " $R$ " sound though it is difficult as we do not have a complete reading.

The next letter is " ") ". I have not yet managed to read this. It is probably "sha". But I am not certain about this.

The "Min "sign comes next. There is a small diacritic in it. I read it as "Ma".

The next character is " ". This is similar to the water sign " 4 " in Protocuneiform. (MEAPage 236).The initial reading which was given to this was "Tha", based on the Tamil word "Thanni" The last letter is "An". This character has been called the Vase sign. No relation between a vase and the sound "An" is available. This is probably a phallic symbol, similar to th Protocuneiform" LUGAL" . AAN basically means Man in Tamil and Malayalam. 
Now we have a partial reading of "Ru ? Ma Tha An". There is a God in South India generally called "Maadan". There are several versions of this God including Chudalai Maadan etc. The question was whether to use "Tha" or "Da" as the term for the water sign. "Ru ? Maa dan". Examination of the Brahmi script quickly shows that while there is no similarity between "Tha "or its variants and this sign there is a definite correlation to " $\mathrm{Da}$ "

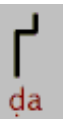

The term is probably derived from Brahui word for water - "Deer".

So the completed reading is "Ru ? Ma Da An. This seems to be a seal depicting an early form of Siva and is probably the source of the term Mahadev.

The next seal would be Fig -2(CP- page 137-M1179).

AN DA

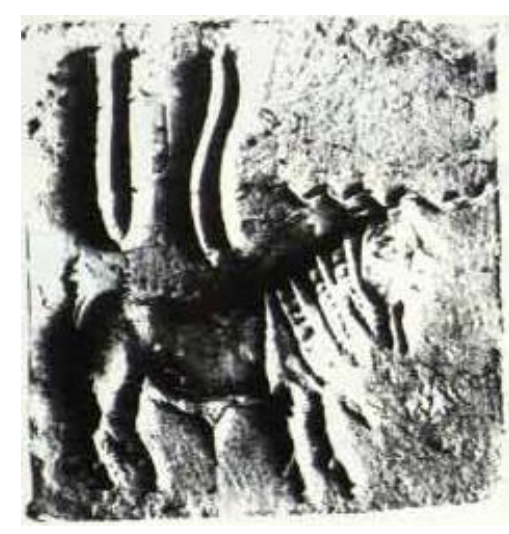

DA AN

The first letter is " $\mathrm{Da}$ ", as explained earlier. The next letter is " $\mathrm{An}$ ". The reading seems to be an attempt at spelling a common caste name. The completed reading would be "Adan". There is a picture of a goat in the seal. The term for goat is "Aadu" in almost all Dravidian languages. The reading is an attempt to spell a common caste name in Northern India - Yadav. This would be Yadavan in Dravidian languages and hence the reading above. Yadav caste has traditionally been associated with cattle herding. This reading proves that the prior reading is probably correct. 


\section{Meaning of Seals}

The question is what do these seals mean. The first seal is obviously the name of a God, with the figurine of the God in it. Why this was used as a seal is unknown. Perhaps it was used in relation to religious artefacts.

The second seal is a standard seal. It states an identification marker. Almost all subsequent seals will be of this kind. More complex seals will state the proper name, caste name and Right Hand/ Left hand divisions in various combinations. Some will only combine one or two elements. These would be employed using various characters for similar sounds though certain characters seem to be used by specific groups.

Idangai(Left Hand) and Valangai(Right hand) tribes (Appadurai, 1974)

Further seal readings would demand an understanding of the Right Hand and Left-hand caste divisions that existed in Southern India. Castes were divided into either Valangai or Idangai. This basically means Right Hand and Left Hand. Essentially, society was divided into 2 divisions with castes either belonging to the Idangai faction or to the Valangai faction.

The Idangai faction consisted of 5 artisan castes initially called Anchalar / Panchalar. The Valangai faction involved agricultural castes and numbered about $60-70$. But these divisions varied between places. There were numerous castes added on to the Idangai and Valangai groups. Some groups would be in Idangai in one place and Valangai in another. (Appadurai, 1974)

The Paraiyan caste was called Valangaimutran. le The Member of Valangai. (Thurston)

Five basic castes in Idangai are

Kannar - Bronze smiths

Asari- Carpenter

Kollan - Blacksmith 
Kaikollan - Weaver

Thattan- Goldsmith

Now these vary, and in some places Thatchan/ Mesthiri/ Saliyan etc are added. In modern times Palli seemed the important group in Tamilnadu. This same system with variations is seen in Karnataka and Andhra.

The separation of artisan communities from The antiquity of this arrangement can be derived from the fact that the Sumerian word for jeweller is KABSAR (KAB = Left). (Labat.R)

There were numerous Valangai castes. The Paraiyan caste was called Valangaimutran/ Valangai moughatan. Roughly translated as chief of Valangai. Readings of Valangai and Paraiyan are possible from Indus seals. However, a full reading of valangaimutran is not available. On the other hand, a reading of Idangaimutran/Idangaimoughatan is available. The Saliyan caste is also denoted as Valangai in Indus script.

The next two seals will need to be read together

Fig- 3
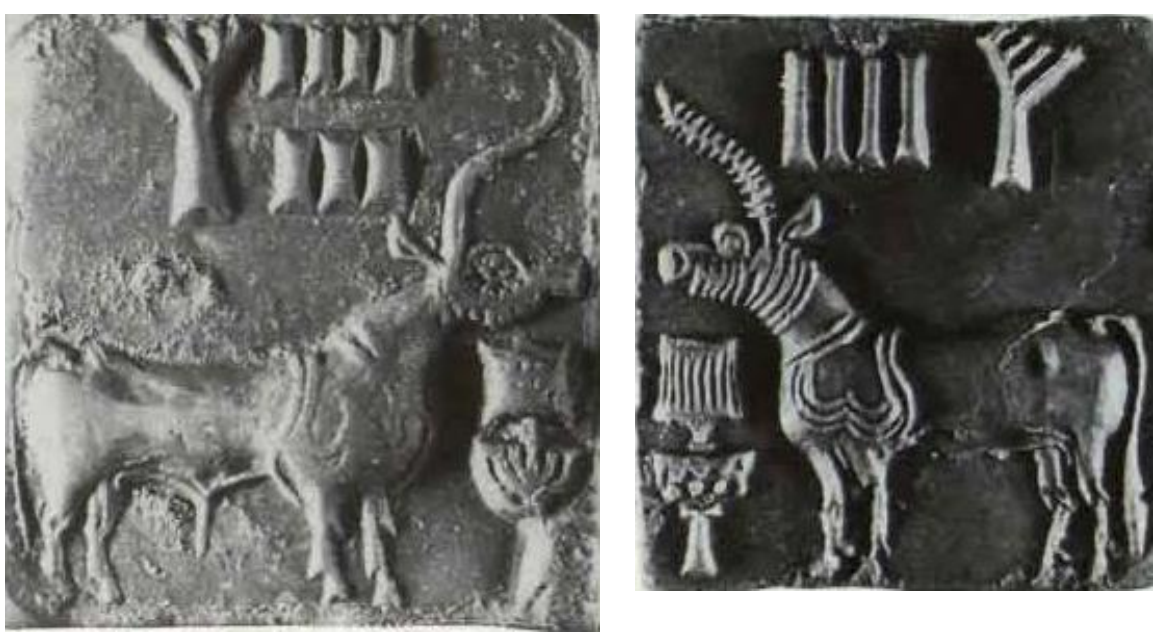
The First seal - CP- Page 33 M676

The first letter is the number seven. This motif is very common throughout the corpus. We can examine the words for seven in Dravidian languages.

$$
\begin{aligned}
& \text { Ezhu - Malayalam } \\
& \text { Elu - Tamil } \\
& \text { Edu - Telugu } \\
& \text { Elu - Kannada }
\end{aligned}
$$

The second letter is $Y$. This is similar to the hand sign in protocuneiform(MEA- Page 162). The word for hand in almost all Dravidian languages is "Kai".

This information lets us read the seal. This is "Edu Kai", otherwise "Idangai".

Confirmation would be from the Brahmi letters for "Kai"

$$
\begin{aligned}
& \text { F } \\
& \text { kai } \\
& \text { and the Brahmi letters for the vowels "i" and "ii" } \\
& \because \quad \because \\
& \text { i ì } \\
& \text { [i] [i: }
\end{aligned}
$$

The vowel form is quite unusual in that it seems to use digits. The most probable reason for this is that it is derived form Edu - Seven. 
The Second seal CP- Page $57-M 749$

The second seal is quite unusual in that it is to be read from left to right .

The first letter is four.

$$
\begin{aligned}
& \text { Malayalam - Nalu } \\
& \text { Kannada - Nalku } \\
& \text { Telugu - Nalugu } \\
& \text { Tamil - Nanku }
\end{aligned}
$$

Combining "Nalu" with "Kai" will give you Nalkai. Obviously when you read Edu Kai as Idangai ,This is to be read as Valangai.

The "Idangai" and "Valangai" divisions in the castes of South India is what is reflected here.

Remnants of this usage could be behind tribal divisions among the Bakhtiari tribe in Iran. This tribe, one of the most ancient nomads of Fars province, speaks a language called Lori language and is divided into divisions called ChaharLang and Haft Lang. These words mean Four leg and Seven leg. The origins of these divisions are currently unknown. But from these readings, it would seem that they would have meant Right Leg and Left Leg in antiquity. These meanings would have slowly disappeared with time leaving only the digit usage. (Encyclopedia Iranica - Baktiari Tribe)

These are not the only characters used to denote Idangai and Valangai.

Multiple characters are used with the meanings of "Idam", "Valam" and "Kai".

Idam:

"IIII, $\infty$ 
Valam:

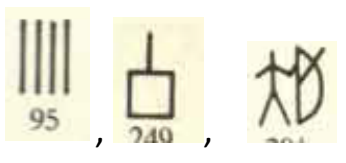

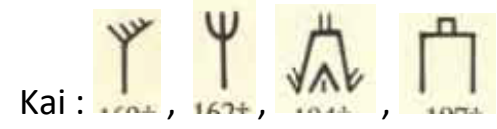

Some of these are obvious as is the use of the "Archer" character which will be "Villali" in Tamil and Malayalam. This gets translated as "Valam".

With regards to Idangaian, For example (CP - Page 23-M644) the last segment of the seal is Idangaian. The sign used for Kai here is the most common sign used in relation to Idangai.

AN KAI EDU AN ? AN KAN ? ?

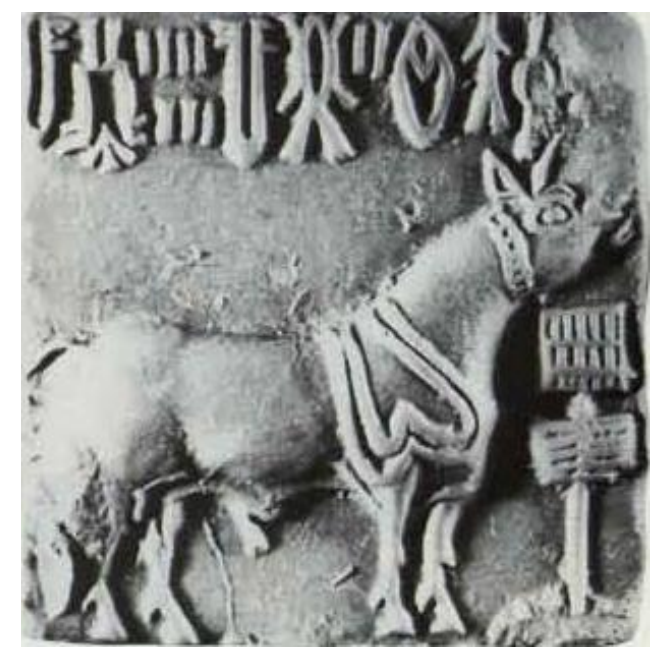

?? KAN AN ? AN IDAM KAI AN.

Fig- 4

An explanation here. The assumption that $\sqrt{A}$ sign is read as Kai is made from the relative

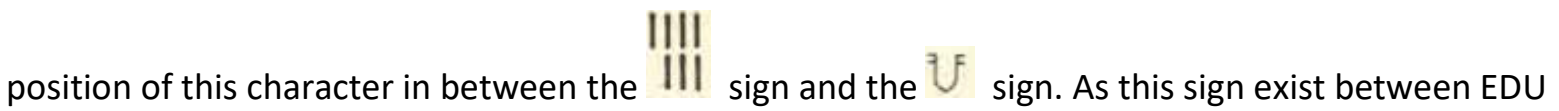


and AN, this is very likely to read as KAI. This is a very common reading and seems to be predominantly used in this particular position. Two other characters were read using their relative positions. This particular symbol is only used with Idangai and gives very good readings overall. The KAN reading is explained later.

CP- Page $45-M 714$ ) the last segment is Idangaian

AN KAI EDU

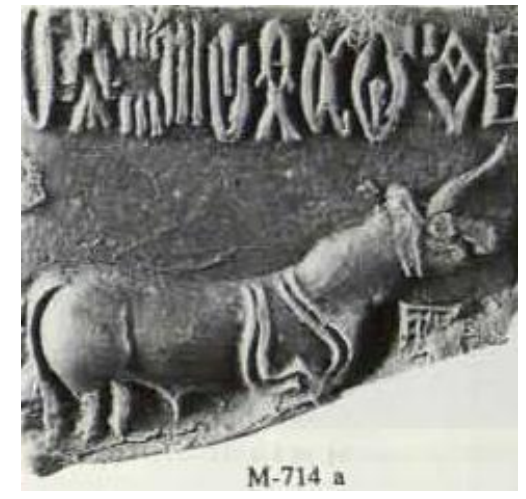

???????IDAM KAI AN

Fig- 5

CP- Page $50-M 728$ ) This uses a different character. But is almost certainly Idangaian. It might seem AN KAI EDU ?

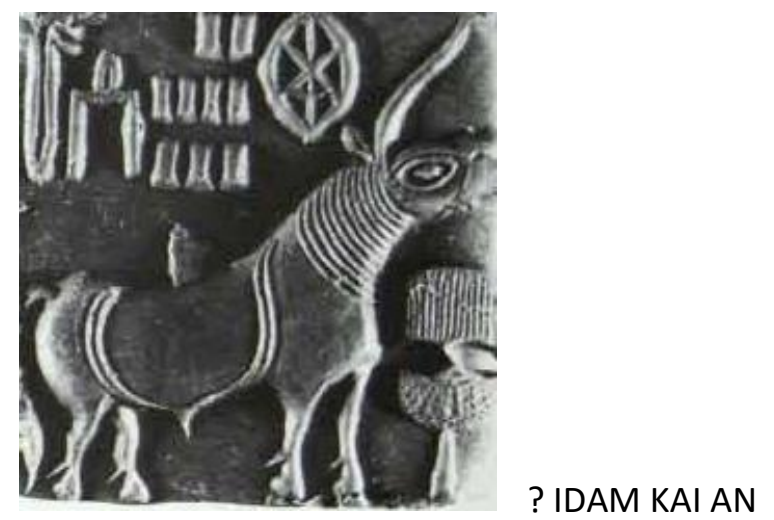

Fig- 6

that there are nine lines here. But the top two lines are actually a diacritic for the first character.

This particular reading provides another character used in this particular position and having the KAI 
sound. The same character will be seen in other settings. However this particular character seems to be used for Idangai and Valangai

Similarly, readings of "Valangai" can be made in several seals. The predominant character used to write "Valam" is not the digit "Four". It is a specific character seen in this seal.

CP -Page 33- M- 672)

AN KAI VAL ?

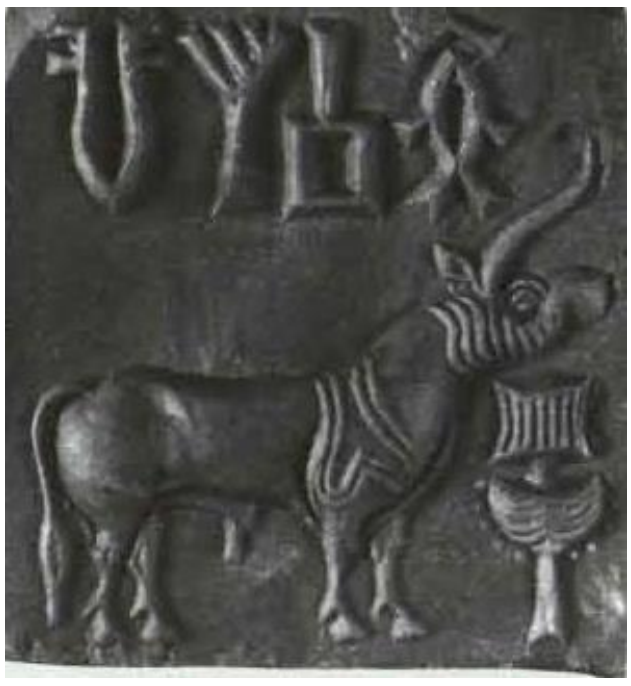

? VAL KAI AN

Fig- 7

The first character is unknown. The last three characters mean Valangaian. The second character is spelled VAL. The closest cognate that I can find in Protocuneiform is "KUN" (MEA - Page 72). This means tail in Sumerian and would sound "Val" in Tamil, Kannada and Malayalam. The Brahmi letter "Va" $\begin{aligned} & \qquad \\ & \text { va }\end{aligned}$ 
(Cl- Page $43-\mathrm{M} 131)$

AN KAIVALAR KAI ?

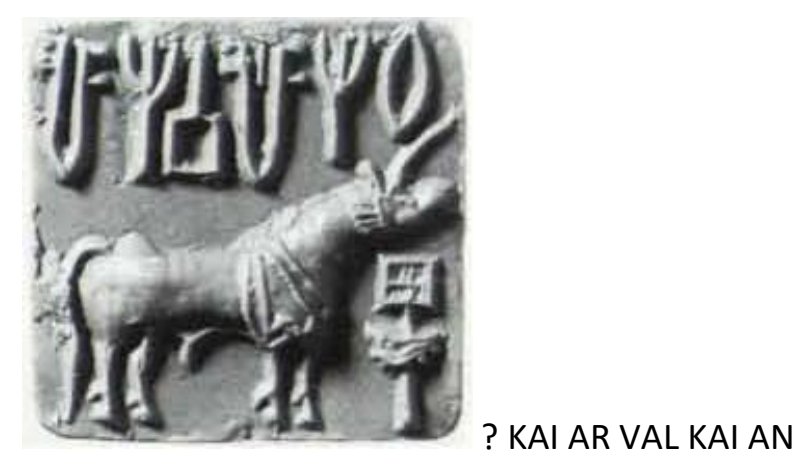

Fig- 8

You can notice here that the "Kai" sign is slightly different. This is similar to the plant sign in

Protocuneiform and probably means "Kaira". In the word it is spelt "Kai". This seems to be the most common sign used to denote "Kai" in the corpus. There are two sections, the initial section is also a "Kaiyar". The AN seems to have been slightly modified with a line. This is probably read as AR. This is not $\mathrm{AN}$ as the line would be unnecessary. It is related to $\mathrm{KAl}$ and the possible reading is one of KAI AR. The seal seems to read Idangaiar Valangaian, if the first character is read as IDAM. This is very uncertain.

The next seal is from Mohenjodaro

( Cl - Page $107 \mathrm{M} 1063$ )

KAI VAL. ?

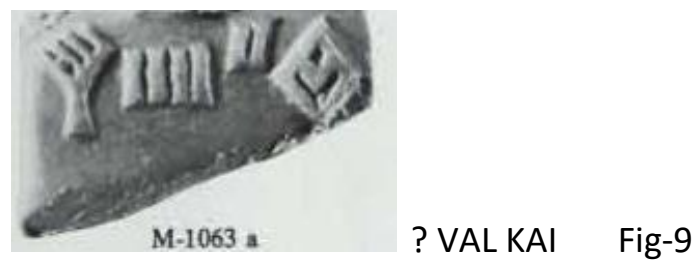

A simple Valangai reading. The first character is uncertain. The diacritic qualifies the first character hence it is probably a caste name. The middle and last character reads as Valangai 
An interesting variant is seen in (Cl- Page 202- $\mathrm{H} 156)$.

AN IDAMKAI

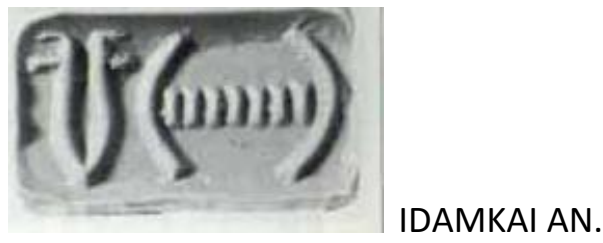

Fig - 10

This is read as "Idangaian". The brackets seem to indicate a hand. If the brackets are read as a hand, we will find further interesting readings.

Further readings are possible with regards to the castes involved.

It would seem straightforward to obtain further readings once the Right hand and left hand caste names are identified. Sadly, this is not so. The system seems to have been different in the IVC, though similarities can be ascertained.

The diacritic " seems to be used as "AN/AR". That helps us to read multiple seals. Several signs seem to be used with both Idangai and Valangai. Among these are some of the most used signs in the Corpus.

There are three usual signs associated with both Idangai and Valangai. These are likely to be some form of caste names.

\section{$" \otimes 1 \otimes$}

Only a tentative reading of the last one has been made.

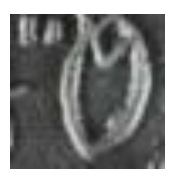


This is read as "KAN". The basic reason is that the shape seems to resemble an eye.

This associated with the diacritic" , would be read as "KANNAN".

A characteristic reading is

(CP- Page - 64 M776)

AN IRU MUTTA KAI EDU AN KAN

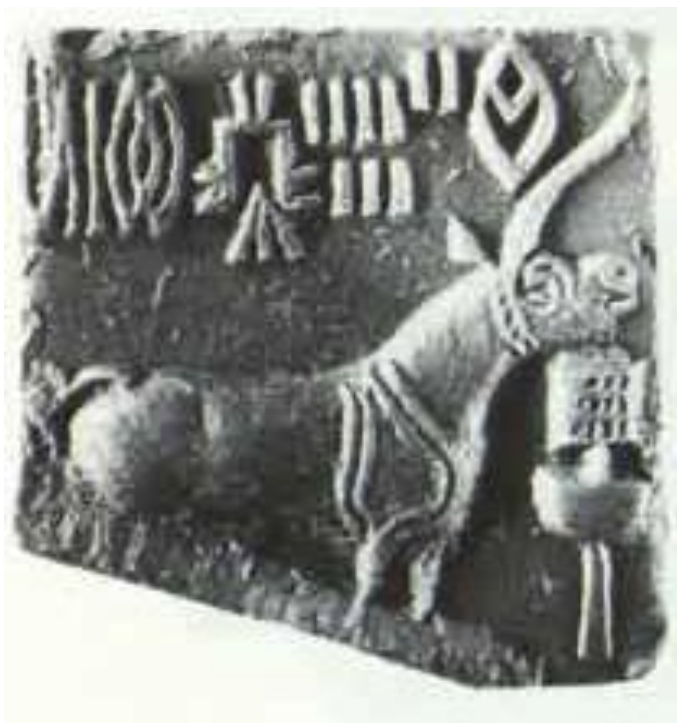

Fig - 11

KAN AN IDAM KAI MUTTA IRU AN

The interlocking ovals are to be read as "MUTTA" the Dravidian word for egg. This is similar to Protocuneiform "NUNUZ". (MEA - Page 180) Though we have interlocking circles instead of a line between them. The Brahmi letter for "Tta" $\bigodot_{\text {tha }}$ is a circle. The two lines after the egg sign would have to be read as 'Iru', the general Dravidian word for two. So the complete reading would be "Kannan Idangai mutran". Kannan caste is not known to be called as Idangai mutran in any literature currently available. This is possibly an ancient form . 
(Cl- Page 345. B10 and B12)

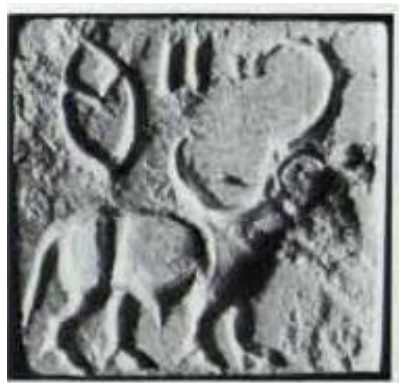

B-7 A

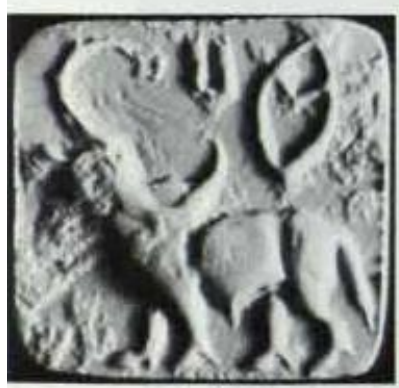

B-7 a

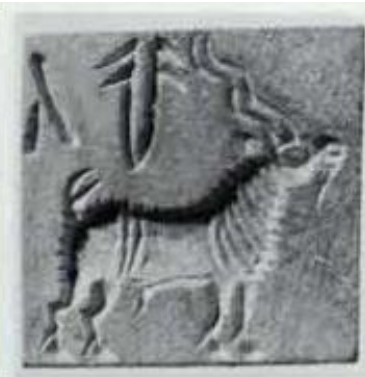

B-8 A

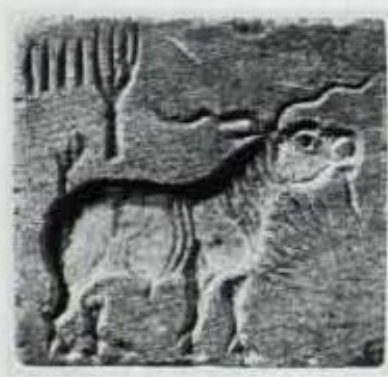

B.9. A

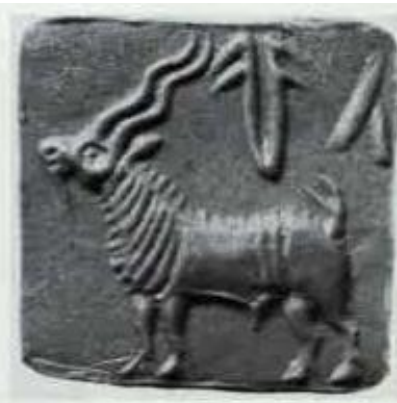

B-8 a

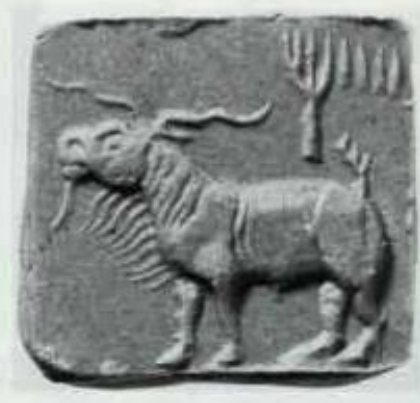

B -9 a

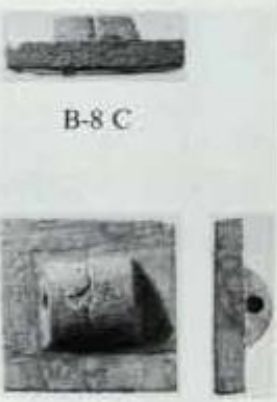

B- 8 B

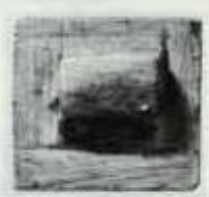

B.9 B

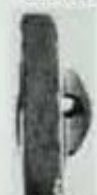

B-9 D

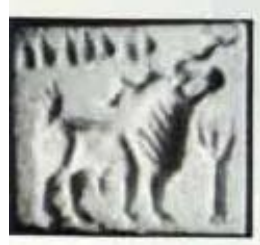

B-10 A

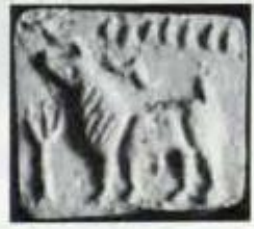

B-10 a
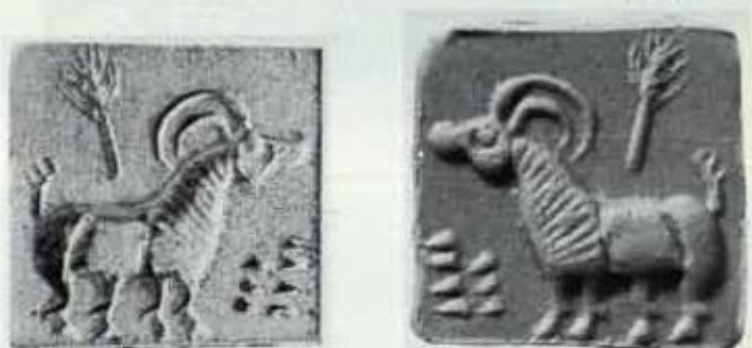

Fig - 13

B- 7 KANNAN, B-8-THIR AN, B9 VAL KAI B10-IDAM KAI, B12-IDAM KAI

Page 345 of Corpus( India ) shows multiple interesting readings.

B7 is a simple reading and states Kannan.

B8 shows a different character and probably means "Thiran". But that is a very uncertain reading dependent upon similarity between this and certain Protocuneifrom characters.

B9 is a simple Valangai reading. 
$\mathrm{B} 10$ and B12 are Idangai readings in various forms. The Kai of B12 shows the origin of the "Kai" with three fingers. It is probably derived from the Sumerian word for plant/ oil palm etc as has been explained earlier. The interesting aspect is the liberties that the seal maker has taken with the script. The IDAM is in one place and the KAl iis in another place. There is an implicit certainty that they would be read together and that they would not be mistaken for anything else.

One more Idangai reading

(Cl- Page 258. L-84)Kannan Idangai

IDAMKAI KANNAN

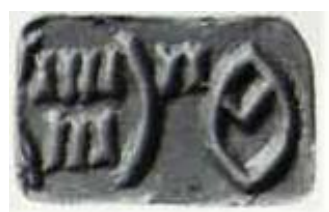

L-84 a KANNAN IDAM KAI. $\quad$ Fig- 12

Valangai.

Several further readings of Valangai are available throughout the Corpus.

(CP- Page199 M 1452B)

AN KAI VAL

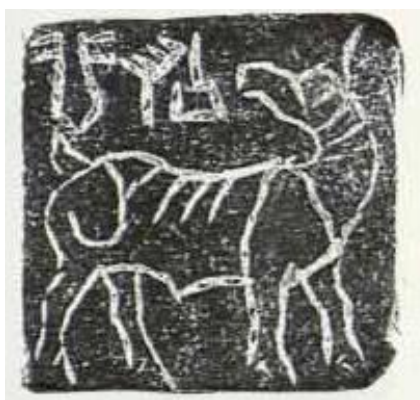

VAL KAI AN

Fig- 14 
This is a simple and straightforward reading. It says ValKaiAn.

The particular reading is from an inscribed copper plate.

The best reading for Valangai would be from (CP-Page 56, M746)

AN PAR MIN IRU AR KAI VAL?

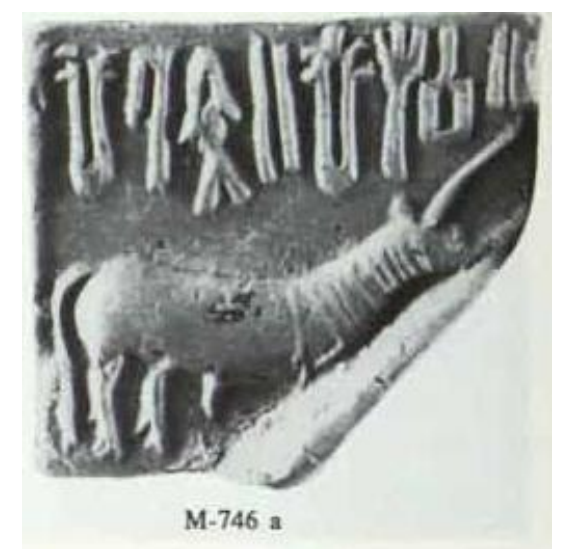

? VAL KAI AR IRU MAN PAR AN. $\quad$ Fig- 15

This introduces a new character " ". This is similar to a Sumerian term "PAR". (MEA Page - 68)

.This means "side/ other side". All the words for "side"in Dravidian languages seem derived from

Sanskrit "Paksha" in one way or another.. The Tamil word is "Pakkam", Kannada is "Bhaga",

Malayalam is "Vasham" etc. Using the Sumerian term would give a reading for the terminal portion

as "PAR AN" - Parayan. The Brahmi letter "Pa" would be cognate .The "2" sign is to be read as "IRU".

The fish sign is "MIN". The reading except for the first character would be

"ValanKaiAr IruMan ParAyan". This is probably Valankaiar Raman Paraiyan

This reading can be seen in 2 seals. 
The second seal is (CorpusPakistan - Page 271 H420)

KAI NALU AN PAR? ?

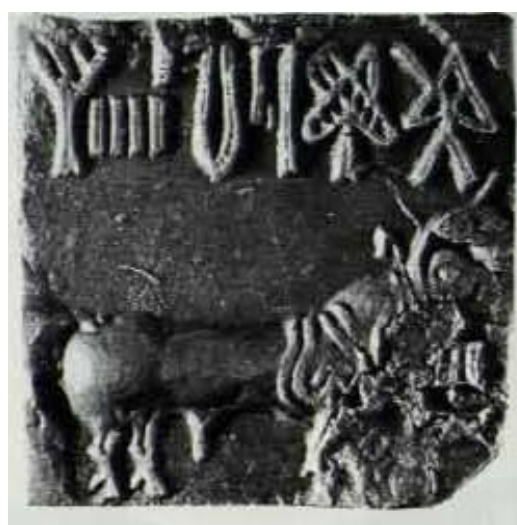

Fig- 16

The first and second signs are uncertain. The terminal portion however would be Par Ayan Valam Kai. Again this is an uncertain reading.

The Idangai castes were also called Anchalar/Panchalar. You can find straightforward examples of this throughout the corpus.

AN LA ANCH

(Cl- Page $44 \mathrm{M} 138$ )

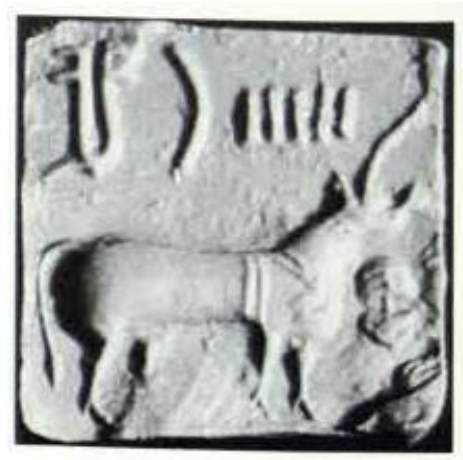

M.130.. ANCH LA AN

Fig- 17

The reading is selfexplanatory except for the "LA" part.The first part in 5- Anchu in Malayalam/ Tamil. The curved sign is to be read as" LA". If this sign is read as "LA" several further readings can be 
obtained. MEA Page 174 gives a possible cognate LIS from Protocuneiform.

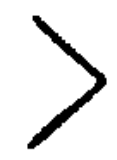

Another reading which is essentially the same is in Corpus Pakistan Page $286 \mathrm{H} 511$

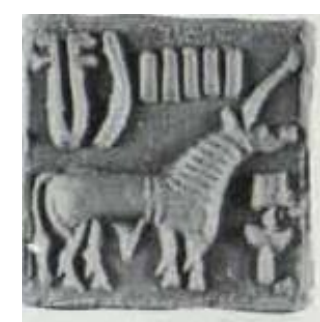

H.511 a

ANCH LA AN Fig- 18

We also get combined readings. However here we have complications. As I mentioned earlier the Idangai tribes were called Anchalar. However in some readings we find Valangai Anchalar.

Corpus Pakistan Page 81 M878

AN LA ANCH AR KAI VIL

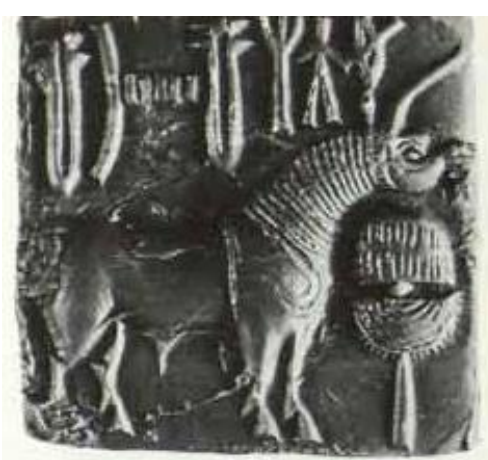

M-878 a

VIL KAI AR ANCH LA AN

Fig - 19

The fist character is a man holding a bow. "VIL". This is followed by a "KAl". This is followed by the "AN" sign. I read this as "AN" in this instance. So the whole reading would be Valangaiar Anchalan. Now it is uncertain why this is so. But the conclusion must be that the divisions were not very solid 
at this time. There are several instances in modern times of fluid divisions in the Right hand and lefthand castes. Palli for example have people belonging to both sides of the division.

The next reading is more straight forward Corpus India - Page $181 \mathrm{H} 50$ AN KAI VAL AR KAI VIL

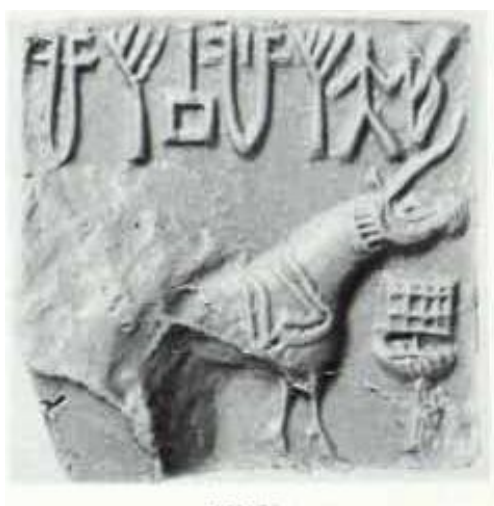

VIL KAI AR VAL KAI AN Fig - 20

This reads simply as Valangaiar Valangaian

There are further straightforward readings

For ex- Corpus India - Page 53 M- 194

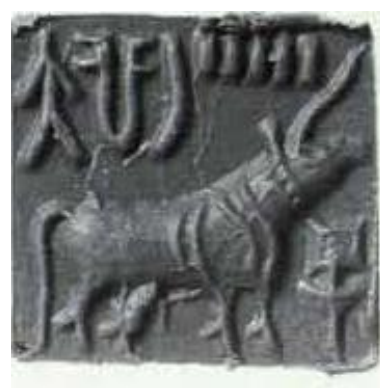

ANCH LA AN ? $\quad$ Fig -21

The terminal sign is unread. The set of signs prior to it read as Anchalan. 
The next reading would be Corpus Pakistan

Page 168 M1307

AN. MALA ANCH

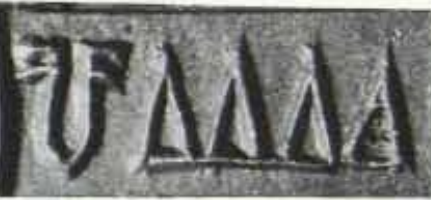

Fig - 22

The word is very common and seem to be used like Anchalan. The first letter similar to Protocuneiform character<smiles>C1=CC=C1</smiles>
, MEA Page 44 "ZU", This means 'to know'. The Malayalam word is "Arinju", Tamil "Therinju". might be derived from this. Reading it as Anchu will give a reading of Anchalan and let us read several other seals. The second word is MALA -meaning Hill, mountain etc. This seems to be used for the LA part only in this reading.

For example Corpus India Page 27 M58

AN MALA ANCH KANNAN

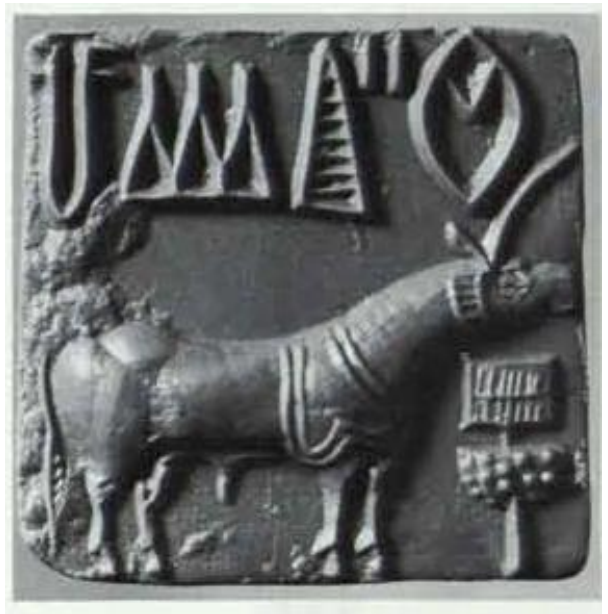

Fig - 23 
This is to be read as Kannan Anchalan. The Kannan part has been explained in a previous paper. The Anchalan part is to be read as above. Once we read this as "Kannan Anchalan" further readings which are essentially the same can be seen.

For example, Corpus India Page 11 M14

AN MALAR ANCH KANNAN

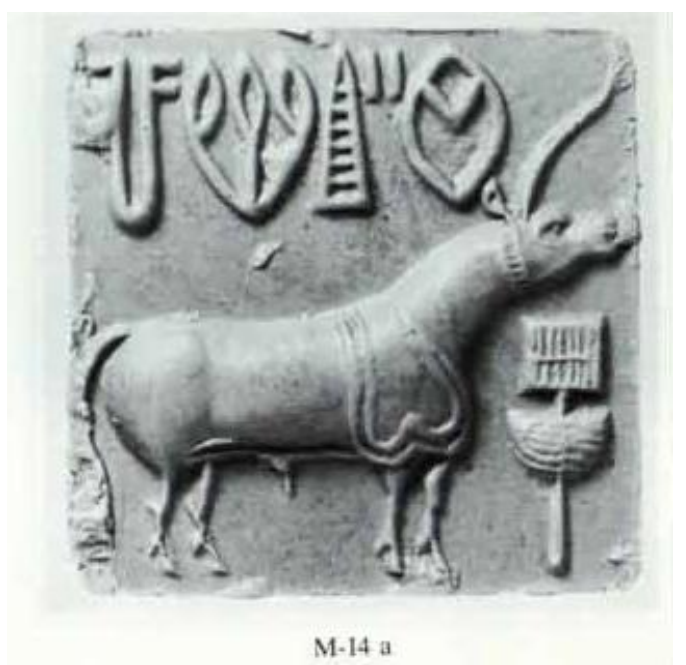

Fig- 24

. The whole reading is essentially the same as the previous one except for the central character. This is shaped like a flower and incidentally the word for flower in Tamil is "Malar". Using the "LA" as the sound involved you would get a reading for Kannan Anchalan.

There are multiple similar readings. The central character in the seal at the bottom is similar to the character for cloth in Protocuneiform. The closest reading which fits is VALA the word for net in Tamil. $\quad$ AN VALA ANCH

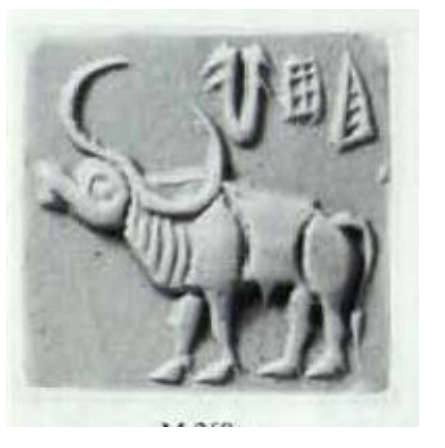


Fig - 25

This seal is from CP- Page $140-$ M559. This uses the same structure however with an additional character

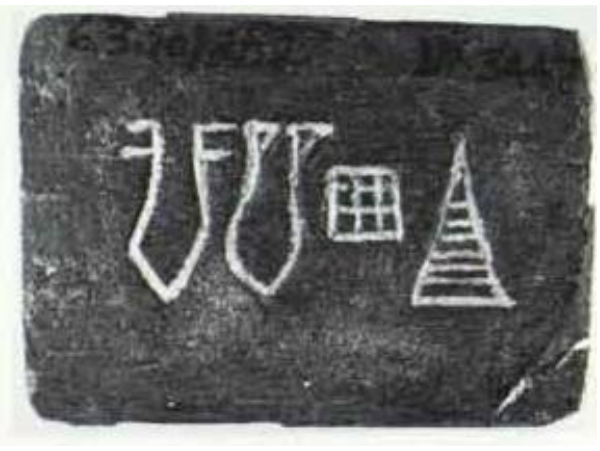

Fig - 26

There are 2 caste names associated with weaving. The first one is Saliyan or Chaliyan . The name is derived from the spider(Chilanti- Tamil and Malayalam)Saliyans are generally associated with the Right hand group, while another weaver caste called KaiKollans were of the left hand group.

Both the seals underneath seem to indicate a spider followed by a man holding a bow(VilValam=Right) and a character which seems to indicate the Hand sign. So, the reading seems to indicate Saliyan Valangaian followed by some characters which have not been read so far. 
. The writing of M624 is from left to right. It may have been a seal in which the reading was reversed, or this was done on purpose to indicate some sort of difference from the normal. The original seal for Right hand group also has a reading from Left to Right. So it may be part of the design.
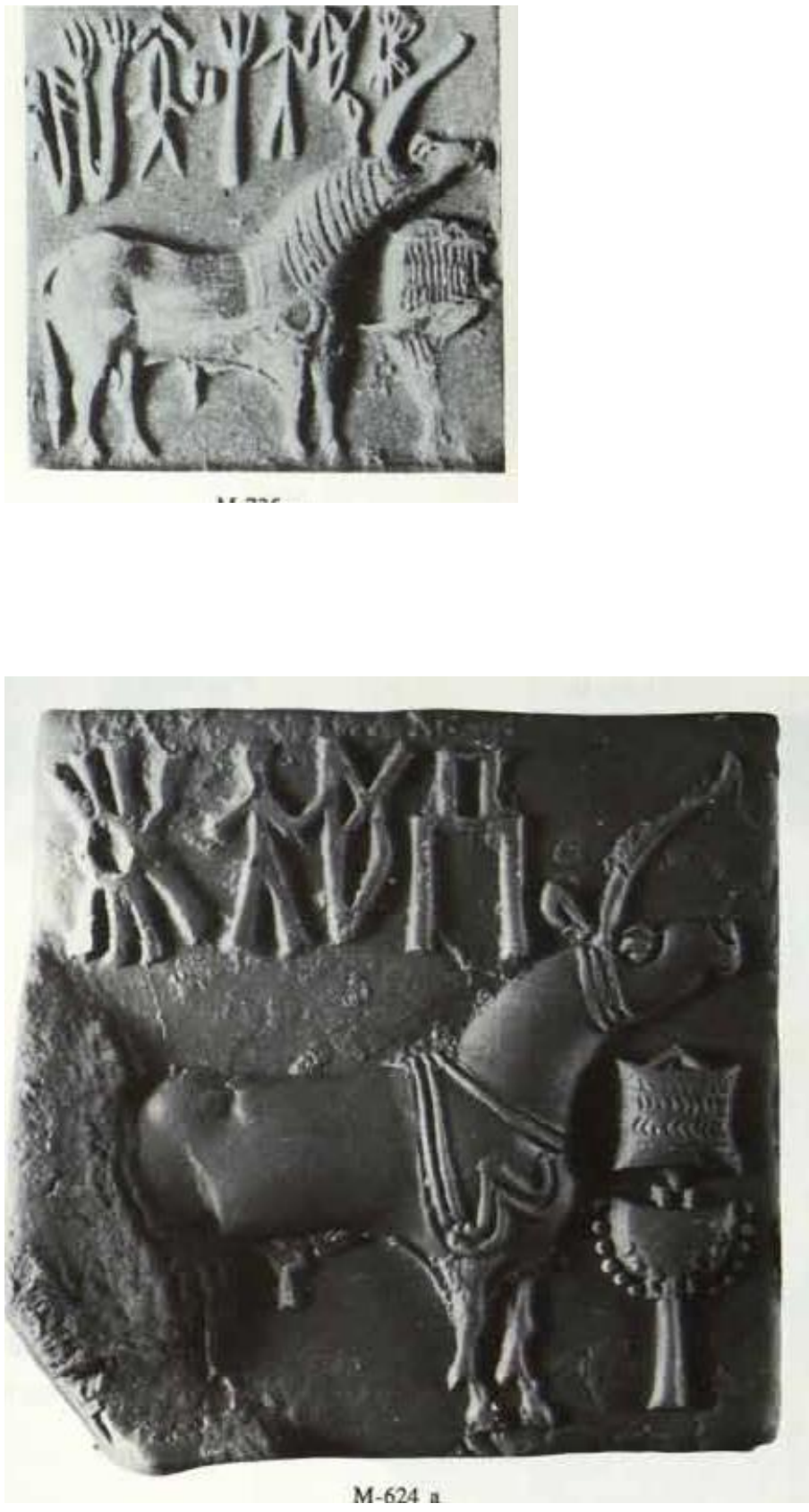
This also seems to show a spider and a man holding a bow. This is followed by a character which has already been read as Kai. So, this would be read as Saliyan Valamgai.

Readings of KaiKollan

AN KAIKOLI ? ? ?

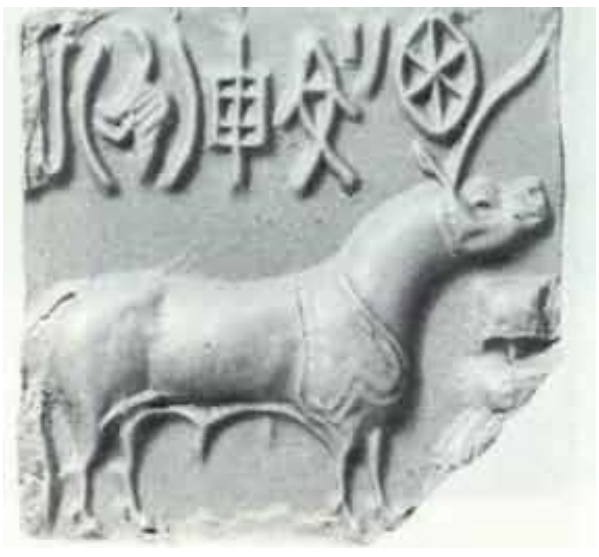

Fig- 28

The last portion seems to show a bird inside parentheses. The parentheses is to be read as KAl as earlier explained. The word for hen in Tamil and Malayalam is Koli. This can be read as Kai kolan.

There is one more reading with similar characters.

\section{AN. LA ANCH KAIKOLAN?}

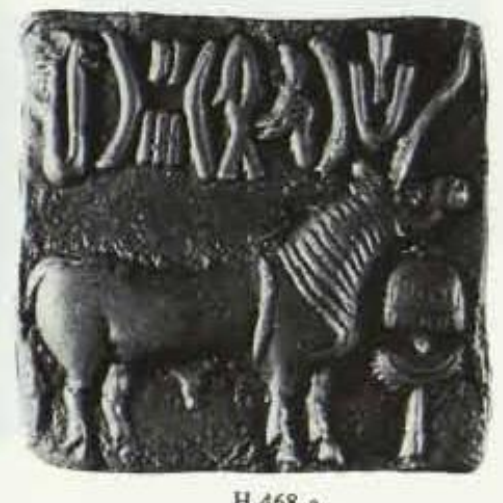

?KAI KOL MIN ANCH LA AN

Fig- 29

The first character has not been read. The characters inside the parentheses can be read as

Kaikolumin. The Min here is to be read as 'An' and the reading will be Kaikolan. The five lines are read 
as Anchu. La is the next character. An is the last character. So the partial reading except for the first character would be Kaikolan anchalan. This fits in with our explanations so far.

Multiple readings of Idamkai and Valamkai are available throughout the corpus.

The Right hand/Left hand caste divisions are probably quite ancient. In addition to what has been mentioned about Kabsar- metal worker/ jeweller in Sumerian, the caste divisions in Africa show extensive evidence of the existence of artisan castes. (Plotnikov, 1970)

Hence these divisions are from an early stage of civilisation and probably were present in Indus valley. These divisions are present to this day in India and are occasionally the source of minor issues among the depressed castes in India.

\section{Conclusion}

The paper provides two primary conclusions. The first is that Indus valley script is a writing system. It is Logosyllabic as expected. The script seems to be derived from Protocuneiform. This is quite logical considering the close links between Indus valley and ancient Mesopotamia as is evident from several sources. Second is that Brahmi script is at least partially derived from Indus script. I have pointed out several similarities in the paper.

There are other secondary conclusions. The first would be that Indus valley civilisation is Dravidian in nature. The fundamental argument here is the existence of evidence of Right Hand and Left hand caste systems in Indus valley civilisation. This peculiar system is only present in Southern India and is a remnant of what must have existed in a Pan Indian distribution earlier. This distribution of people into 2 vertical divisions in itself seem to be a form of a social stratifications system that spans a large region extending from Northern Africa to India. This provides another interesting conclusion. This would be that the caste system existed in India prior to Aryan invasion. 
The probability that the reading is correct is quite high. It would be highly unlikely that random readings would be able to generate words which correspond precisely to extant social structures. For example the parentheses character can be used to read Idam Kai and Kaikollan. This is further evidence that the readings are correct. Certain further inferences can be made. The relation between KABSAR and jeweller have been mentioned earlier. There is further evidence of the spread of this division in Persia and even to Greece. The Bakthiaria tribe of Persia, an ancient tribe is divided into two groups. The HaftLang and Chahar Lang, which basically means Seven Legs and Four Legs. (J.P. Digard) The origin of this division has been lost in antiquity. On reading these seals it becomes obvious that the division was initially Left Leg and Right Leg. The meanings were lost in time and only the words remained. It is possible that the name of the Greek God Hephaestus is derived from this division as well. Hephaestus is the god of artisans and the origin of the name is unknown. It is possible the name originally meant Haft Haestus. Haft is seven in several Indo European languages including Kurdish, Persian etc and it is possible the original name just meant Left Hand.

\section{Bibliography}

(n.d.). Retrieved from https://docplayer.net/65165255-Caste-dispute-riots-and-the-englishcompany.html

A.Parpola, J. J. (1987). Corpus of Indus seals and Inscriptions.

Appadurai, A. (1974). Right and Left hand Castes in South India. The Indian Economic and Social History review.

Encyclopedia Iranica - Baktiari Tribe. (n.d.).

https://www.omniglot.com/writing/brahmi.htm. (n.d.).

Labat.R. (n.d.). Manuel D Epigraphie Akkadienne. 
Plotnikov, T. A. (1970). Social Stratification in Africa.

Thurston, E. (n.d.). Castes and Tribes of Southern India Volume -6 Paraiyans. 
